\title{
A Pediatric Case of Tuberculous Osteomyelitis of the Mandible Mimicking a Bony Malignant Tumor
}

\author{
Alaoui Siham Mehdaoui1,2*, Asmae Akhana1,2, Karim Gharnati1,2, Dounia Kamal1,2, \\ Abdellatif Oudidi1,2, Mohammed Noureddine Elalami El Amine1,2 \\ ${ }^{1}$ Faculty of Medicine and Pharmacy, Sidi Mohammed Ben Abdellah University, Fez, Morocco \\ ${ }^{2}$ Department of Otorhinolaryngology, Head and Neck Surgery, Hassan II Hospital, Fez, Morocco \\ Email: *siham.alaoui.m@gmail.com
}

How to cite this paper: Mehdaoui, A.S., Akhana, A., Gharnati, K., Kamal, D., Oudidi, A. and El Amine, M.N.E. (2021) A Pediatric Case of Tuberculous Osteomyelitis of the Mandible Mimicking a Bony Malignant Tumor. Journal of Tuberculosis Research, 9, 103-109.

https://doi.org/10.4236/jtr.2021.92009

Received: May 5, 2021

Accepted: June 21, 2021

Published: June 24, 2021

Copyright $\odot 2021$ by author(s) and Scientific Research Publishing Inc. This work is licensed under the Creative Commons Attribution International License (CC BY 4.0).

http://creativecommons.org/licenses/by/4.0/

(c) $\underset{\mathrm{By}}{\text { (i) Open Access }}$

\begin{abstract}
Background: Tuberculosis is a granulomatous infectious disease which is still being a real health problem in developing countries. Mainly, this specific infection affects pulmonary sites, but, the occurrence in extra-pulmonary sites is more and more reported. However, when extra-pulmonary tuberculosis affects the cervico-facial region, the cervical lymph nodes are the most involved. Aim: Throughout this case report, we put emphasis on keeping in mind of the possible tuberculous infection in a chronic lesion of mandible in children. Case presentation: In this article, we present a case of a 2-year-old child who was complaining of swelling of the right angle of the mandible. The computed tomography showed an osteolytic lesion suggesting tuberculous osteomyelitis but didn't rule out a bony malignant neoplasm of the mandible. The histological examination of biopsy of the lesion proved the tuberculous osteomyelitis of the mandible. The child has received anti-tubercular therapy for 9 months, and she marked a good recovery. Conclusion: In children, tuberculous osteomyelitis of the mandible is a curable disease without sequel when diagnosis is given at the right time.
\end{abstract}

\section{Keywords}

Tuberculosis, Mandible, Child, Biopsy, Drugs

\section{Introduction}

The tuberculosis is a worldwide infectious disease that is still being a serious health problem, especially in the developing countries. Even though tuberculosis is a preventable and curable disease, it continues to impact the lives and devel- 
opment of millions of children and adolescents [1]. In 2019, 2081 pediatric cases of tuberculosis were recorded in Morocco, and in contrast, extrapulmonary tuberculosis was more notified ( $81 \%$ of these cases): lymph nodes sites were more frequent (45\% of cases) among this population under 15-year-old [2]. However, the tuberculous osteomyelitis is a very rare entity occurring most commonly in vertebras and long bones, and the occurrence in the mandible is exceptional [3]. Mandible involvement usually affects older individuals, and in pediatric population, the spread of infection may be through a mucosal opening associated with an erupting tooth or by regional extractions of soft tissue lesions to underlying bone or hematogenous spread [4]. In this paper, we present a case of tuberculous osteomyelitis of the mandible occurring in a 2-year-old child.

\section{Case Report}

A 2-year-old girl child, suffering from anemia and without contact history of tuberculosis, presented to our department with swelling adjacent to the right angle of mandible, progressively growing during two months, without recovery after a period with antibiotics drugs. Physical examination found feverish girl, with a unilateral swelling over the right angle of mandible, extending up to the submandibular region. This swelling was painful, hard in consistency, fixed to the underlying structures with blurred limits, the overlying skin was normal and without inflammatory signs, measuring $4 \mathrm{~cm}$ and causing a facial asymmetry (Figure 1). The intraoral examination showed also a swelling in the right inner cheek and the retromolar trigone without purulent discharge or ulcerated lesion. There was no trismus and the teeth were in good condition (Figure 2). The orifice of the Stenon canal was normal. We didn't notice any cervical lymphadenopathy. Hematological and biochemical investigations revealed a biological infectious syndrome (Table 1):

An ultrasound neck features showed the presence of an adenophlegmona of submandibular region measuring $36 \times 23 \mathrm{~mm}$ with infiltration of the surrounding fatty tissues. Then, the patient was started on intravenous antibiotics using Ceftriaxone $50 \mathrm{mg} / \mathrm{kg} /$ day, Metronidazole $15 \mathrm{mg} / \mathrm{kg} / 8$ hours and Gentamicin 3 $\mathrm{mg} / \mathrm{kg} /$ day for one week, consequently, the biological infectious syndrome has improved steadily, however, the swelling was persistent.

A computed tomography of the neck and face was carried out with contrastenhancing: In the bone window (Figure 3), it revealed an osteolytic lesion involving the right angle of mandible with extension into the adjacent ramus and inferior border of body of mandible with bony fragmentation. In the soft tissue window (Figure 4), there was associated a multilocular abscess and infiltration of surrounding soft tissue with microcalcifications. Right submandibular lymph nodes were also present. Findings were suggestive of tuberculous osteomyelitis, but a malignant bone neoplasm was not excluded.

The patient underwent an intraoral incision and drainage of the abscess as well as a bony biopsy to obtain specimen of the suspected lesion. The histopathological examination revealed caseating necrosis with the presence of Langer- 
hans giant cells and epitheloid cell granulomas (Figure 5). Then, the diagnosis of tuberculous osteomyelitis of the mandible was confirmed, based on clinical and histopathological findings. The chest radiograph showed no evidence of pulmonary tuberculosis (Figure 6).

Table 1. Results of hematological and biochemical investigations.

\begin{tabular}{cc}
\hline Biological investigations & Results \\
\hline Hemoglobin level & $8.50 \mathrm{~g} / \mathrm{dL}$ \\
Total leukocyte counts & $28.6 \times 10^{3} \mathrm{cells} / \mathrm{mm}^{3}$ \\
Neutrophils & $19.9 \times 10^{3} \mathrm{cells} / \mathrm{mm}^{3}$ \\
Lymphocytes & $6.09 \times 10^{3} \mathrm{cells} / \mathrm{mm}^{3}$ \\
C-reactive protein & $139 \mathrm{mg} / \mathrm{L}$ \\
\hline
\end{tabular}

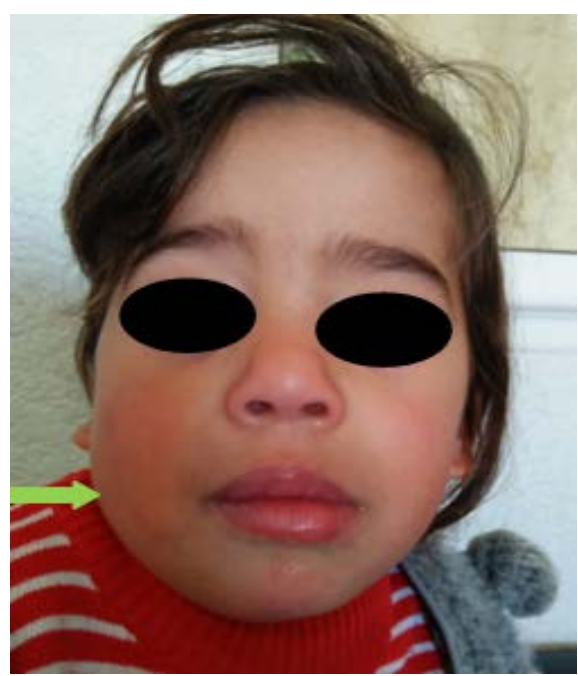

Figure 1. Clinical view showing a swelling over the right angle of mandible.

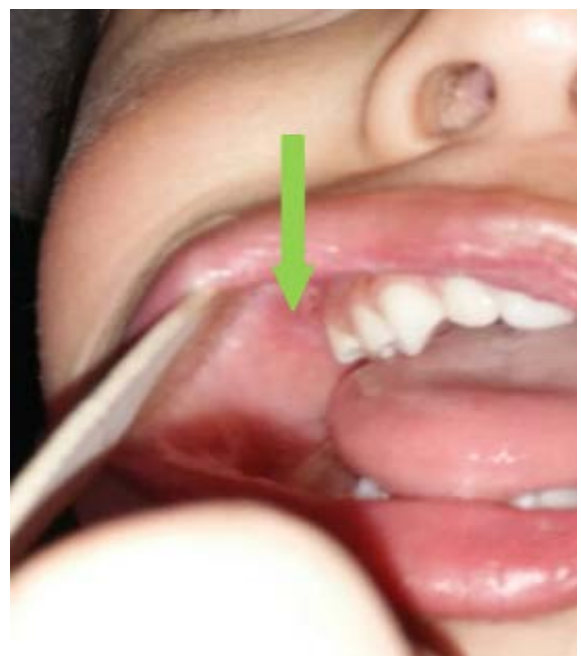

Figure 2. Intraoral examination showing a swelling in the right inner cheek. 


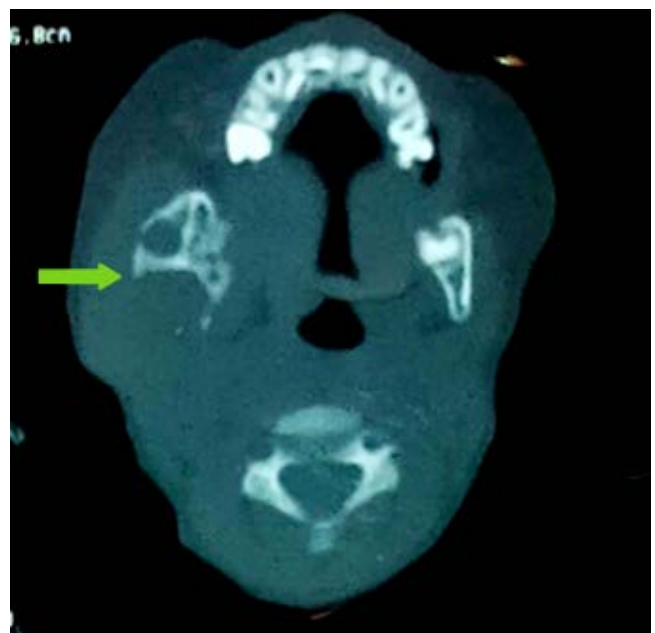

Figure 3. CT scan imaging revealing an osteolytic lesion of the right angle of mandible with cortical expansion (bone window).

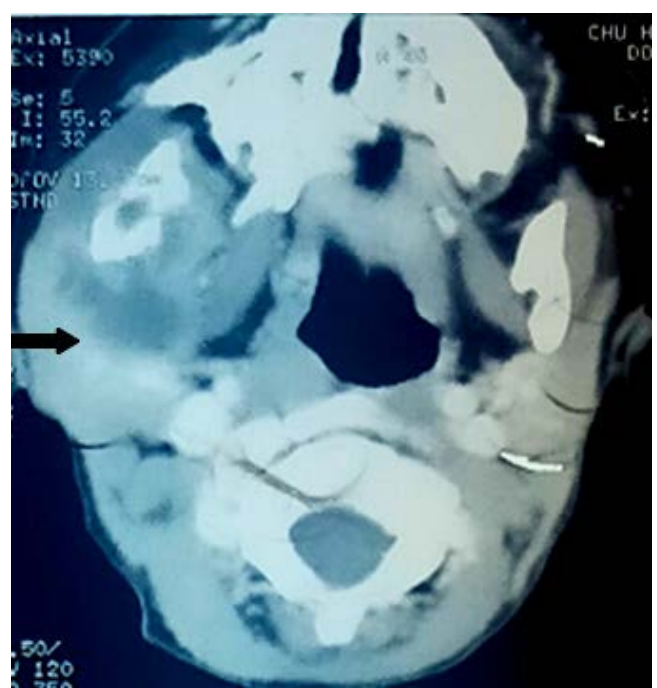

Figure 4. CT scan imaging revealing a multilocular abscess and infiltration of surrounding soft tissue (soft tissue window).

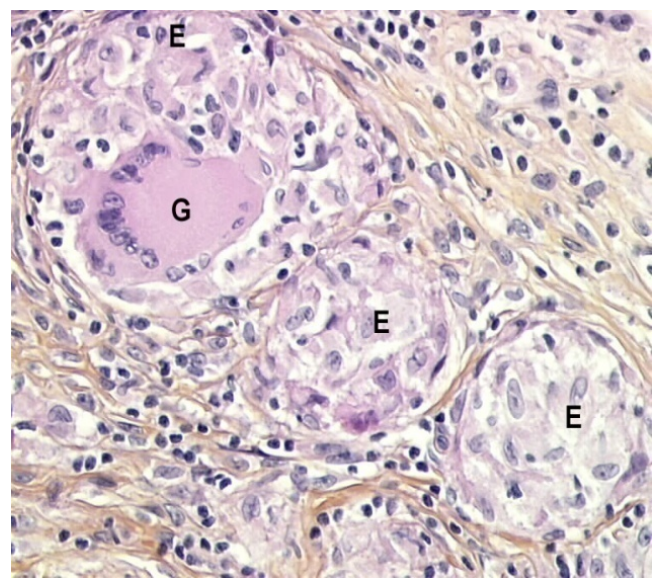

Figure 5. Histopathological examination showing the presence of Langerhans giant cells (G) and epitheloid cells (E) granulomas. 


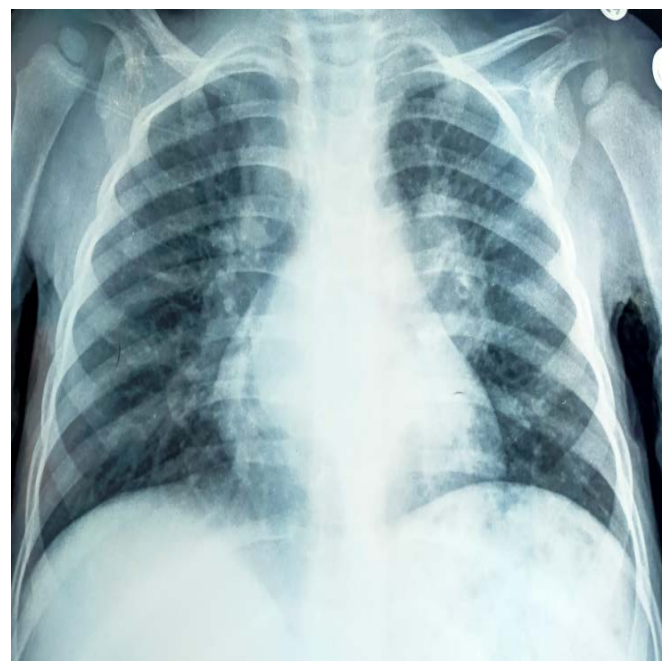

Figure 6. Chest radiograph showing no evidence of pulmonary tuberculosis.

The patient was started on antitubercular therapy: Rifampicin $15 \mathrm{mg} / \mathrm{kg}$, Isoniazid $10 \mathrm{mg} / \mathrm{kg}$, Pyrazinamide $35 \mathrm{mg} / \mathrm{kg}$ during the two first months (Initial Phase) followed by seven months using Rifampicin and Isoniazid (Continuation Phase), associated with a good nutritious diet and strict oral hygiene care during 9 months. A regular follow-up, taking into account the side effects associated with antituberculosis drugs, regular tests of the hepatic enzymes and kidney function were performed during the treatment course. With the ongoing treatment, the swelling subsided gradually in size with time, and complete resolution of the lesion was obtained after 3 years of follow-up.

\section{Discussion}

In children and teenagers, tuberculosis is one of the biggest causes of morbidity and mortality over the world. Then, the tuberculosis incidence among this population is a sensible indicator reflecting the control level of this disease in a country. In Morocco, pediatric cases of tuberculosis presented 7\% of all cases in 2019 (versus $17 \%$ in 1980), though, osteoarticular tuberculosis presented $1 \%$ of all sites [2]. Tuberculosis occurrence in mandible is very rare and is seen in less than $2 \%$ of all skeletal locations [5] [6]. The propagation of tuberculosis infection to the mandibular bone is mainly happened via a hematogenous route, spread from neighboring tissue, mucosal lesion during teeth eruption or by direct inoculation through dental extraction [7].

Clinical presentations of tuberculous involvement of mandibular bone may be various from periodontitis, apical osteitis to widespread destructive lesions. Sequestrations may be present, and pathological fracture of mandible is also reported [8] [9]. Sheikh et al. reported a case that presented a sudden onset of dull pain at the temporomandibular joint associated with reduced mouth opening [10]. The most-reported presentation is a progressive swelling of the cheek adjacent to the mandible [3] [4] [6]. 
Radiologically, the findings are no specific to tuberculous osteomyelitis: erosion of cortical bone is gradually replaced by a sub-periosteal abscess responsible of the painful swelling [11]. However, they may lead to suspect this specific infection and to confirm the diagnosis by other investigations.

Chaudhary et al. reported that Fine needle aspiration cytology (FNAC) can be helpful to make diagnosis; it demonstrates a granulomatous area with numerous giant and epitheloid cells surrounded by lymphocytes and plasma cells [4]. Histological examination is mandatory to confirm the diagnosis by showing a caseating or non-caseating granuloma with scattered Langerhans giant cells and epitheloid cells [3] [10].

In our case, radiological findings suggested a tuberculous osteomyelitis of the mandible, however, malignant bone neoplasm like Ewing's sarcoma or an osteogenic sarcoma were not excluded, because all of these lesions may present the same image features (osteolytic lesion and cortical erosion) [12]. Consequently, incisional biopsy was obligatory to make the right diagnosis.

According to our national guide of antitubercular therapy in children [2], the osteoarticular tuberculosis is treated by the following association: during the initial phase, we use Rifampicin $15 \mathrm{mg} / \mathrm{kg}$, Isoniazid $10 \mathrm{mn} / \mathrm{kg}$, Pyrazinamide 35 $\mathrm{mg} / \mathrm{kg}$, Ethambutol $20 \mathrm{mg} / \mathrm{kg}$, and during the continuation phase, we use Isoniazid and Rifampicin. Apart from resistance of Mycobacterium, recovery is the rule after an antitubercular therapy well established.

\section{Conclusion}

Tuberculous osteomyelitis of the mandible is a rare disease in children, but we have to keep it in mind when the lesion of the mandible is chronic and doesn't recover after empiric antimicrobial therapy. Then, a histological examination is mandatory to make the right diagnosis and rule out other granulomatous or malignant lesions. The antitubercular therapy must be begun as soon as possible to reduce the disease morbidity.

\section{Acknowledgements}

We are grateful to all the staff that was involved in the care of this patient.

\section{Consent}

Consent from the patient's parents was obtained for publication.

\section{Conflicts of Interest}

The authors declare no conflicts of interest regarding the publication of this paper.

\section{References}

[1] (2018) Roadmap towards Ending TB in Children and Adolescents-Second Edition. http://apps.who.int/iris/bitstream/handle/10665/275422/9789241514798-eng.pdf?ua 
$=1$

[2] (2020) Guide national de prise en charge de la tuberculose chez l'enfant et l'adolescent. https://pharmacie.ma/uploads/pdfs/Guide\%20PEC\%20TB\%20enfant\%20et\%20ado \%20\%20Maroc.pdf

[3] Saurabh, S., Mall, B.B., Somani, R. and Mishra, A. (2014) Tuberculous Osteomyelitis of the Mandible: A Rare Case Report. Journal of Indian Academy of Oral Medicine \& Radiology, 26, 439-441.

https://www.jiaomr.in/article.asp?issn=0972-1363;year=2014; volume=26;issue $=4 ;$ sp age $=439$; epage $=441$; aulast $=$ Saurabh https://doi.org/10.4103/0972-1363.155645

[4] Chaudhary, S., Kalra, N. and Gomber, S. (2004) Tuberculous Osteomyelitis of the Mandible: A Case Report in a 4-Year-Old Child. Oral Surgery, Oral Medicine, Oral Pathology, and Oral Radiology, 97, 603-606. https://doi.org/10.1016/j.tripleo.2003.10.032

[5] Imamura, M., Kakihara, T., Yamamoto, K., Imai, C., Tanaka, A. and Uchiyama, M. (2004) Primary Tuberculous Osteomyelitis of the Mandible. Pediatrics International, 46, 736-739. https://doi.org/10.1111/j.1442-200x.2004.01992.x

[6] Berkia, I., El Kharras, A., Darbi, A., Chaouir, S., Amil, T., Benameur, M., et al. (2007) Tuberculose primitive de la mandibule: À propos d'un cas. Journal de Radiologie, 88, 1193-1195. https://doi.org/10.1016/S0221-0363(07)89933-1

[7] Tellez-Rodriguez, J., Lopez-Fernandez, R., Rodriguez-Jurado, R., Moreno-Sandoval, H.N., Martinez-Perez, F. and Gonzalez-Barrios, J.A. (2016) Mycobacterium tuberculosis as a Cause of Mandibular Osteomyelitis in a Young Woman: A Case Report. Journal of Medical Case Reports, 10, Article No. 366.

https://www.ncbi.nlm.nih.gov/pmc/articles/PMC5175378/ https://doi.org/10.1186/s13256-016-1118-x

[8] Erasmus, J.H., Hompson, I.O.C. and van der Westhuijzen, A.J. (1998) Tuberculous Osteomyelitis of the Mandible: Report of a Case. Journal of Oral and Maxillofacial Surgery, 56, 1355-1358. https://doi.org/10.1016/S0278-2391(98)90623-1

[9] Sambyal, S.S., Dinkar, A.D., Jayam, C. and Singh, B.P. (2016) Primary Tuberculous Osteomyelitis of the Mandible in a 3-Year-Old Child. BMJ Case Reports, 2016, 7 p. https://www.ncbi.nlm.nih.gov/pmc/articles/PMC5051373/ https://doi.org/10.1136/bcr-2016-216854

[10] Sheikh, S., Pallagatti, S., Gupta, D. and Mittal, A. (2012) Tuberculous Osteomyelitis of Mandibular Condyle: A Diagnostic Dilemma. Dentomaxillofacial Radiology, 41, 91-179. https://doi.org/10.1259/dmfr/56238546

[11] Koul, P.A., Khan, U.H., Jan, R.A., Shah, T.H., Bagdadi, F. and Shah, S. (2014) Tubercular Osteomyelitis of the Mandible in a Young Female. International Journal of Mycobacteriology, 3, 155-157.

https://www.sciencedirect.com/science/article/pii/S2212553114000144 https://doi.org/10.1016/j.ijmyco.2014.02.002

[12] Pandarinath, B.G. and Kushal, S. (2012) Ewing's Sarcoma of the Mandible: A Case Report. International Arab Journal of Dentistry, 3, 4 p.

https://ojs.usj.edu.lb/ojs/index.php/iajd/article/view/76 